\title{
Weight Status, Physical Activity and the Associations with Health Related Physical Fitness in Nine to Twelve Year Old Scottish Children
}

\section{David T Gray, Julien S Baker and Duncan S Buchan*}

Institute for Clinical Exercise and Health Science, School of Science, University of the West of Scotland, Hamilton, ML3 OJB, Scotland, UK

\begin{abstract}
Purpose: This study examines the associations of both BMI and waist circumference measurements to health related physical fitness.
\end{abstract}

Methods: The sample included 43 boys and 49 girls (10.7 \pm 0.89 years). Measures included height, weight, BMI and waist circumference, physical activity (PAQ-C) and measures of physical fitness; cardiorespiratory and muscular fitness.

Results: Girls were stronger on the handgrip test $(P=0.045)$ and had a higher BMI than boys $(P=0.041)$. Boys performed better than girls for the standing broad jump $(P=0.006)$ and cardiorespiratory fitness shuttle run $(P=0.030)$ but not on the handgrip test. $29 \%$ (37\% of girls and $21 \%$ of boys) of participants were either overweight or obese. Participants with a higher BMI performed significantly poorer than their healthy counterparts on the standing broad jump $(P=0.003)$ and cardiorespiratory fitness shuttle run $(P=0.002)$. Similar results were found in the larger waist circumference group, standing broad jump $(P=0.044)$ and cardiorespiratory fitness shuttle run $(P=0.032)$. Finally, participants with a higher $\mathrm{BMI}$ or waist circumference had a greater score for the hand grip test $(P=0.006 ; P=0.004)$.

Conclusion: Early detection of poor weight status and low physical fitness are important so that those in need of intervention can be targeted as early as possible.

Keywords: Physical fitness; Children; Adiposity

\section{Introduction}

Obesity is now considered a global concern throughout the Western world, due to its increasing prevalence. It is now well established that the occurrence of poor weight status in both children and youths appears to be increasing for all ages with recent findings suggesting that the prevalence of obesity in 6 to 11 year olds increasing from $6.5 \%$ in the 1980 s to approximately $20 \%$ in 2008 [1,2]. It is well established that cardiovascular disease has its origins in childhood with high levels of adiposity often associated not only with an increased risk of adult obesity, but also with a number of immediate health risks that can be associated with cardiovascular disease, such as hypertension $[3,4]$. For this reason it has become vital to recognise children with a high risk at the earliest opportunity, so that an intervention programme can be put in place to prevent later onset of adverse health profiles.

The benefits of both physical activity and fitness are well established, as numerous studies have highlighted that an advanced capacity of cardio respiratory fitness in childhood is often associated with an improved cardiovascular profile in both childhood and adulthood $[1,5,6]$. Similar findings have been expressed with regards to physical activity with those that are more active demonstrating a reduced risk of coronary heart disease, hypertension, stroke and type 2 diabetes in adulthood [7,8]. Regardless of the well-established benefits of both physical fitness and physical activity, evidence suggests that children are opting for a sedentary lifestyle, with countless failing to achieve the minimal activity guidelines $[9,10]$. Recent findings published in Scotland portray a worrying figure, with approximately one in three (35\%) of Scottish adolescences aged 2 to 15 years of age apparently unable or unwilling to achieve the minimal activity guidelines [11]. These findings are worrying due to the well-established associations between physical inactivity and being overweight and obese $[12,13]$. It has been suggested that poor physical fitness may be a more powerful predictor for poor health than physical activity [14]. Unfortunately there is a lack of evidence which has documented the associations between physical fitness and weight status. Thus, the purpose of this study was to determine the associations between weight status, physical activity and health related physical fitness in nine to twelve year-old Scottish children. Since risk factors often track from adolescence into adulthood, information detailing the associations between weight status and physical fitness is potentially relevant to the development and implementation of preventive measures and effective intervention strategies.

\section{Materials and Methods}

\section{Sample}

A group of children $(\mathrm{N}=43$ boys and 49 girls, $10.7 \pm 0.89$ years of age) from a West of Scotland primary school volunteered to participate in the study. The sample included children from primary five $(\mathrm{N}=12$ boys and 9 girls), six ( $\mathrm{N}=20$ boys and 14 girls) and seven $(\mathrm{N}=11$ boys and 26 girls). Only the participants who returned completed consent forms were eligible for the study. All tests and measurements were fully explained to all participants beforehand. All pupils were reminded that they were free to withdraw from the study at any time and were assured of anonymity.

\section{Anthropometric measures}

Stature, without shoes, was measured to the nearest $1 \mathrm{~mm}$ (Seca Stadiometer, Seca Ltd., Birmingham, UK). Weight in light indoor

${ }^{*}$ Corresponding author: Duncan Buchan, Institute of Clinical Exercise and Health Science, University of the West of Scotland, Almada Street, Hamilton South Lanarkshire ML3 OJB, Scotland, UK, Tel: 01698 283100; E-mail: duncan.buchan@uws.ac.uk

Received September 04, 2013; Accepted September 19, 2013; Published September 26, 2013

Citation: Gray DT, Baker JS, Buchan DS (2013) Weight Status, Physical Activity and the Associations with Health Related Physical Fitness in Nine to Twelve Year Old Scottish Children. J Sports Med Doping Stud 3: 129. doi:10.4172/21610673.1000129

Copyright: $\odot 2013$ Gray DT, et al. This is an open-access article distributed under the terms of the Creative Commons Attribution License, which permits unrestricted use, distribution, and reproduction in any medium, provided the original author and source are credited. 
clothing, without shoes, was measured to the nearest $0.1 \mathrm{~kg}$ using calibrated electronic weighing scales (Seca 880, Digital Scales, Seca Ltd. Birmingham, UK). Body Mass Index (BMI) was calculated (weight/ height ${ }^{2}, \mathrm{~kg} \cdot \mathrm{m}^{-2}$ ) and used to classify participants as obese, overweight, underweight, or at a healthy weight using recommended international age and gender-specific BMI cut-off values [15]. Waist Circumference (WC), a proxy measurement of central (abdominal) fat distribution was measured in accordance with standard procedures [16].

\section{Physical Activity}

All participants completed a validated physical activity questionnaire for children (PAQ-C) which required them to detail their physical activity levels from the 7-days [17]. Completed questionnaires were inspected and the responses were clarified verbally to achieve confirmation.

\section{Cardio respiratory Fitness}

Cardiorespiratory fitness (CRF) was assessed with the $20 \mathrm{~m}$ shuttle run test (20MSFT) [18]. All participants were required to continuously run 20 metres, while keeping pace with a pre-recorded CD. The speed was initially set at $8.5 \mathrm{~km} \cdot{ }^{\mathrm{h}-1}$, which increased by $0.5 \mathrm{~km} \cdot{ }^{\mathrm{h}-1}$ each minute [1 minute equates to 1 level]. All participants were asked to continue to run for as long as possible until they reached their maximal effort. The test ended when the participant failed to reach the required line before the audio signal on two consecutive occasions. The 20MSFT is familiar to most children and is accepted as a valid test of CRF where a higher number of completed shuttles indicate a higher level of fitness. Participants score for the 20MSFT was then converted into a $\mathrm{VO}_{2} \max$ value using a well-established equation. The $\mathrm{VO}_{2} \max$ equation $=0.38 \mathrm{x}$ total number of shuttles completed +25.98 [19].

\section{Muscular Fitness}

Muscular Fitness was estimated with the handgrip test through the use of a handgrip dynamometer (Takei A5001 Hand Grip Dynamometer, Takei Scientific Instruments Co., Ltd., Niigata-City, Japan). Hand preference was determined before the testing session began. The test was performed in the standing position with both arms by the participant's side. The protocol consisted of three maximal isometric contractions for 5 seconds, on the participant's favoured hand, with a rest period of at least 60 seconds between each contraction. Subsequently an average of the three scores was calculated to determine the participant's muscular strength. The subjects were instructed to squeeze the dynamometer as hard as possible. Visual feedback of the recorded strength was provided immediately after the participant's attempt.

The standing broad jump was used to measure muscular power. A non-slip gymnasium floor was used for take-off and the take-off line was clearly marked. Participants completed a standardized warm up before attempting a jump. The participant's jump was measured using a tape measure (Freemans Fibre Glass Measuring Tape, FMI Ltd., India) to measure distance jumped. The measurement was taken from take-off line to the nearest point of contact on the landing, back of the heels. The protocol consisted of three maximal jumps with a rest period of at least 60 seconds between each jump. An average of the three scores was used to determine the participant's muscular fitness

\section{Data Analysis}

All statistical analyses were performed using SPSS software, version 20.0 (SPSS Inc., Chicago, Illinois, USA). All variables were tested for normality of distribution beforehand. Significant differences between sexes were determined by an independent-sample t-test. As no significant interaction was found for age, maturation and sex in each cohort, all analyses were performed with boys and girls together to increase statistical power. A partial correlation test was used to determine associations between anthropometric measures and both physical fitness and physical activity measures. Anthropometric and physical fitness characteristics of the study sample are presented as means and standard deviation. The analysis of sex differences were identified using an independent t-test and weight group differences in both the anthropometric and physical fitness were carried out through the use of a univariate Analysis Of Variance (ANOVA) and a Bonferroni correction post hoc. The variable Physical Fitness Score was created using the sum of $\mathrm{z}$-scores $(\mathrm{z}=$ value-mean $/ \mathrm{SD})$ of $\mathrm{VO}_{2} \max$, Number of Shuttles, Standing Broad Jump and Handgrip. The aim of the statistical tests was to determine the differences in outcome variables between genders, age and weight groups. Gender and physical activity was included in all models as covariates with the significance value set at $\mathrm{P}<0.05$ throughout.

\section{Results}

Participant characteristics are summarized in Table 1. Boys performed significantly better than girls on the cardiorespiratory shuttle run test, and the standing broad jump although girls performed significantly better on the handgrip test. Girls also presented with a significantly greater BMI than boys. Significant differences between genders were also apparent for cardiorespiratory fitness (shuttles), Standing broad jump, Handgrip and $\mathrm{VO}_{2}$ max with boys performing significantly better than girls on all fitness tests except for the handgrip test.

Partial correlations for measures of adiposity with physical fitness measures are displayed in Table 2. With regards to BMI, significant positive associations were noted with Handgrip strength whilst significant negative associations were noted between standing broad

Table 1: Descriptive statistics (mean \pm SD) for age, anthropometry, physical fitness, and physical activity variables in children by sex.

\begin{tabular}{|l|c|c|c|}
\hline $\begin{array}{l}\text { Variables } \\
\text { (units) }\end{array}$ & Boys (n = 43) & Girls (n = 49) & P value \\
\hline Age (years) & $10.5 \pm 0.8$ & $10.9 \pm 0.9$ & 0.043 \\
\hline Stature (cm) & $141.8 \pm 7.9$ & $143.8 \pm 8.9$ & 0.268 \\
\hline Body mass (kg) & $38.7 \pm 10.3$ & $43.1 \pm 10.9$ & 0.052 \\
\hline BMI (kg.m-2) & $19.04 \pm 3.7$ & $20.7 \pm 3.8$ & 0.040 \\
\hline Waist circumference (cm) & $63.5 \pm 8.9$ & $63.6 \pm 8.1$ & 0.972 \\
\hline Cardiorespiratory fitness (shuttles) & $18.5 \pm 9.3$ & $15.2 \pm 4.4$ & 0.038 \\
\hline Standing broad jump (cm) & $141.1 \pm 23.8$ & $128.7 \pm 18.2$ & 0.007 \\
\hline Handgrip (kg) & $15.8 \pm 3.7$ & $17.3 \pm 3.4$ & 0.045 \\
\hline VO ${ }_{2}$ max (ml/kg/min) & $24.5 \pm 3.9$ & $23.2 \pm 1.9$ & 0.045 \\
\hline Physical activity (PAQ-C) & $3.06 \pm 0.5$ & $2.9 \pm 0.6$ & 0.211 \\
\hline
\end{tabular}

All variables are presented as mean $\pm S D$. P-value for genders is presented Significance level was set at $(P<0.05)$. Significant values are given in bold.

Table 2: Partial Correlations between BMI, Waist Circumference and Physical Fitness Measures.

\begin{tabular}{|l|c|c|}
\hline Variables (units) & BMI & Waist Circumference \\
\hline $\mathrm{BMI}\left(\mathrm{kg} \cdot \mathrm{m}^{-2}\right)$ & $1.000^{*}$ & $0.766^{*}$ \\
\hline Waist circumference $(\mathrm{cm})$ & $0.766^{*}$ & $1.000^{*}$ \\
\hline Standing broad jump $(\mathrm{cm})$ & $-0.292^{*}$ & $-0.356^{*}$ \\
\hline Handgrip (kg) & $0.432^{*}$ & $0.369^{*}$ \\
\hline Cardiorespiratory fitness (shuttles) & $-0.436^{*}$ & $-0.371^{*}$ \\
\hline $\mathrm{VO}_{2} \mathrm{max}(\mathrm{ml} / \mathrm{kg} / \mathrm{min})$ & $-0.448^{*}$ & $-0.382^{*}$ \\
\hline Physical fitness score & $-0.264^{*}$ & $-0.262^{*}$ \\
\hline
\end{tabular}

*Significant $(P<0.05)$ Association between Weight status measurements. 
Table 3: (mean \pm SD) Cardiorespiratory fitness (shuttles), $\mathrm{VO}_{2}$ max, standing broad jump and handgrip for children overweight/obese and healthy.

\begin{tabular}{|l|c|c|c|}
\hline Variables (units) & $\begin{array}{c}\text { Overweight/Obese } \\
\text { (n= 27) }\end{array}$ & $\begin{array}{c}\text { Healthy Weight } \\
(\mathbf{n}=\mathbf{6 5})\end{array}$ & P value \\
\hline $\begin{array}{l}\text { Cardiorespiratory fitness } \\
\text { (shuttles) }\end{array}$ & $11.9 \pm 3.6$ & $18.7 \pm 7.5$ & $\mathbf{0 . 0 0 2}$ \\
\hline $\mathrm{VO}_{2} \mathrm{max}(\mathrm{ml} / \mathrm{kg} / \mathrm{min})$ & $21.7 \pm 1.72$ & $24.7 \pm 3.1$ & $\mathbf{0 . 0 0 1}$ \\
\hline Standing broad jump (cm) & $120.3 \pm 14.1$ & $140.4 \pm 21.7$ & $\mathbf{0 . 0 0 3}$ \\
\hline Handgrip (kg) & $17.7 \pm 3.9$ & $16.2 \pm 3.4$ & $\mathbf{0 . 0 0 6}$ \\
\hline
\end{tabular}

All variables are presented as mean $\pm \mathrm{SD}$. P-value for BMl category is presented Significance level was set at $(P<0.05)$. Significant values are given in bold.

Table: 4 (mean \pm SD) Cardiorespiratory fitness (shuttles), $\mathrm{VO}_{2}$ max, standing broad jump and handgrip for children in Waist Circumference category.

\begin{tabular}{|l|c|c|c|}
\hline Variables (units) & $\begin{array}{c}\text { Low Waist } \\
\text { Circumference } \\
\text { (n= 40) }\end{array}$ & $\begin{array}{c}\text { High Waist } \\
\text { Circumference } \\
\mathbf{( n = 5 2 )}\end{array}$ & P value \\
\hline $\begin{array}{l}\text { Cardiorespiratory } \\
\text { fitness (shuttles) }\end{array}$ & $18.8 \pm 7.3$ & $15.2 \pm 6.9$ & 0.032 \\
\hline $\mathrm{VO}_{2}$ max (ml/kg/min) & $24.7 \pm 3.1$ & $23.1 \pm 2.9$ & 0.026 \\
\hline $\begin{array}{l}\text { Standing broad jump } \\
\text { (cm) }\end{array}$ & $139.8 \pm 22.0$ & $130.4 \pm 20.8$ & 0.044 \\
\hline Handgrip (kg) & $15.4 \pm 2.8$ & $17.6 \pm 3.9$ & 0.004 \\
\hline
\end{tabular}

All variables are presented as mean $\pm S D$. P-value for Waist Circumference category is presented. Significance level was set at $(P<0.05)$. Significant values are given in bold.

jump, cardiorespiratory fitness, $\mathrm{VO}_{2} \max$ and physical fitness score. Similar results were found with Waist Circumference, as positive associations were noted with Handgrip $(\mathrm{P}<0.05)$ whilst significant negative associations were noted between standing broad jump, cardiorespiratory fitness, $\mathrm{VO}_{2} \max$ and physical fitness score.

Tables 3 and 4 reveal the significant differences between weight status and physical fitness measures. Findings revealed a significant difference between all physical fitness measures and weight status with those classified in the higher weight status group having significantly lower performance measures for Cardiorespiratory fitness (shuttles) $(\mathrm{P}=0.002 ; \mathrm{P}=0.032)$, Standing broad jump $(\mathrm{P}=0.003 ; \mathrm{P}=0.044)$, and $\mathrm{VO}_{2} \max (\mathrm{P}=0.001 ; \mathrm{P}=0.026)$ although Handgrip strength was significantly greater in the higher weight status group $(\mathrm{P}=0.006$; $\mathrm{P}=0.004)$.

\section{Discussion}

The purpose of this study was to determine the associations between weight status, physical activity and health related physical fitness in nine to twelve year-old Scottish children. Findings revealed that girls are taller, heavier and have a significantly higher $\mathrm{BMI}$ than boys $(\mathrm{P}=0.04)$. As expected boys, performed significantly better than girls on almost all of the physical fitness tests, cardiorespiratory fitness $(\mathrm{P}=0.030)$, standing broad jump $(\mathrm{P}=0.006)$ and $\mathrm{VO}_{2} \max (\mathrm{P}=0.045)$. These findings are consistent with previous research $[20,21,22]$. The result from the cardiorespiratory fitness test indicates that boys outperformed the girls by approximately $17 \%$. These findings are consistent with current literature $[21,22]$. These results could be due to small sex differences in muscle mass and haemoglobin concentration prior to puberty, with boys peak $\mathrm{VO}_{2}$ max approximately $10 \%$ higher than prepubertal girls [4]. Boys had a greater $\mathrm{VO}_{2} \max$ than girls $(\mathrm{P}=0.045)$ with results consistent with previous literature $[2,20,21]$.

The standing broad jump demonstrated the highest between genders $(\mathrm{P}=0.006)$, with results indicating that the average boy jumped approximately $9 \%$ further than the average girl. Similar studies have also reported that boys generally outperform girls with regards to jumping [20-22]. However girls significantly outperformed boys on the handgrip test $(\mathrm{P}=0.045)$. The results from this study's population indicate that girls were approximately $8 \%$ stronger than boys according to the handgrip test. Previous studies have discovered otherwise and suggest that boys usually perform significantly better than girls on muscular strength tests such as the handgrip test $[14,20,23,24]$. It could be suggested that these findings are a result of males having a genetically enhanced muscular strength however, it has been proposed that there are no sex differences in muscular strength up until the age of 14 years [4].

Findings from the most recent Scottish Health Survey highlight that $65 \%$ of youths aged 5-16 are currently meeting physical activity recommendations However this figure has been questioned, with a recent study suggesting the figure to be nearer $24 \%[11,25]$. Nonetheless, the measurement of youth physical activity has numerous difficulties, and comparing results from other studies using different methods of acquiring data is challenging. The findings from the present study were acquired through the use of the PAQ-C which measures general activity patterns. It is evident that no significant differences between genders were identified although boys appeared more active than girls. These findings are consistent with current literature which has also suggested that males on average are more active than females [9,23,26,27].

Within this study BMI reported negative associations with standing broad jump, cardiorespiratory fitness, $\mathrm{VO}_{2} \mathrm{max}$ and physical fitness z-score. This suggests that a high BMI has detrimental effects on a child's physical fitness; similar findings have previously been found $[2,3,6,13,28,29]$ (Figure 1). It is well established that a child with a higher level of cardiorespiratory fitness has a healthier cardiovascular profile and appears to suggest that BMI not only has a detrimental effect on a child's physical fitness but also cardiovascular profile $[23,26,28,30]$. However, it was noted that BMI had a moderate association with handgrip strength. These findings are consistent with current literature on adults which suggests that an increased BMI has detrimental effects on cardiorespiratory fitness, power and balance but a positive effect on muscular strength $[26,27]$. This could be due to a higher level of obesity which affects everyday life leading to increased muscular strength. Similar findings were found with regards to waist circumference and physical fitness, as detrimental effects were noted in standing broad jump, cardiorespiratory fitness, $\mathrm{VO}_{2} \max$ and physical fitness z-score (Figure 1and 2).

Significant differences were identified between BMI groups for all physical fitness scores, cardiorespiratory fitness $(\mathrm{P}=0.002), \mathrm{VO}_{2} \max$ $(\mathrm{P}=0.001)$, Standing Broad Jump $(\mathrm{P}=0.003)$ and Handgrip $(\mathrm{P}=0.006)$. These findings are in agreement with the literature which suggests

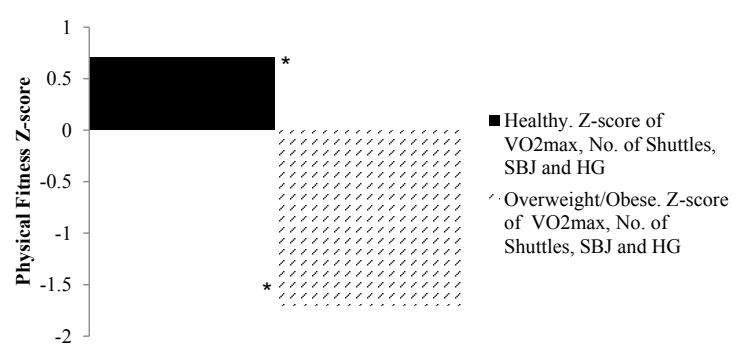

Figure is presented as mean values.

*Significant $(\mathrm{P}<0.05)$ difference between BMI Groups.

Figure 1: Physical Fitness z-score of Shuttles, Standing Broad Jump and Handgrip for each BMI Group. A higher z-score indicates a more favorable physical fitness score. 


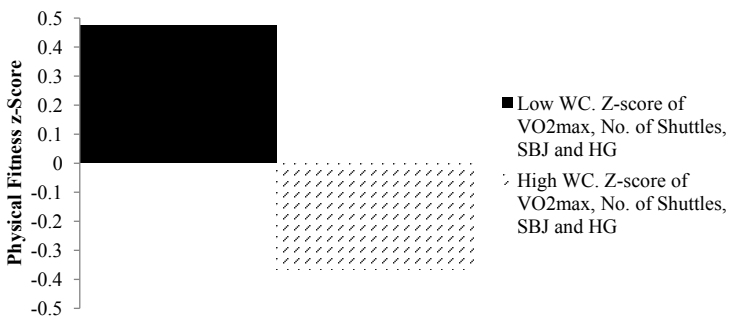

Figure is presented as mean values. No significant difference identified $(\mathrm{P}<0.05)$.

Figure 2: Physical Fitness z-score of Number of Shuttles, Standing Broad Jump and Handgrip for each Waist Circumference Group, a higher z-score indicates a more favorable physical fitness score.

that an overweight or obese individual has a disadvantage performing weight bearing physical fitness tests. Due to the excess body fat which can be seen as an extra load to be moved during weight-bearing tasks [32]. However, it has been proposed that the deficit in weight bearing fitness tests of overweight and obese adolescents was either reduced or even reversed after adjusting for fat mass [14]. These findings could suggest that a non-weight bearing physical fitness test could evaluate the fitness levels more accurately and may explain why the children classified as overweight or obese performed significantly worse on the cardiorespiratory fitness and standing broad jump test, both of which are weight bearing tests.

It is important to note that similar to the BMI results, the children with a larger waist circumference reported significantly greater handgrip strength. Our findings are in agreement with other studies that have identified a positive association between handgrip strength and central adiposity on both Belgian and Flemish youths respectively [32,31]. This greater strength in obese children and adolescents can be explained by their increased fat-free mass since obese individuals develop increased fat-free mass as they accumulate excess adiposity [33]. A significant difference between BMI grouping and physical fitness score was also identified $(\mathrm{P}<0.05)$, however no significant difference was established between waist circumference groups and physical fitness score which suggests that BMI measures is a more powerful predictor of physical fitness in children. This could be due to the assessment of overall adiposity compared to central adiposity on weight bearing fitness test.

From the associations between weight status and physical fitness it was identified that children with a higher BMI or a greater waist circumference performed significantly worse than their counterparts on physical fitness tests that required the individual to exert force against their own body mass. The findings from this study highlight that weight status in Scottish children is a cause for concern as it appears to have a significant association with health related physical fitness. The findings from the present study reinforce that weight status and health related physical fitness in children should be assessed in a clinical practice or school setting, to identify children who are at risk at the earliest opportunity, so that an intervention and preventive strategy can be put in place to help prevent later onset of cardiovascular disease.

The need for further research is evident, Future studies should also involve an intervention to help tackle the weight status and physical fitness problem that is evident within Scottish schools.

\section{References}

1. Eisenmann JC, Katzmarzyk PT, Perusse L, Tremblay A, Després JP, et al. (2005) Aerobic fitness, body mass index, and CVD risk factors among adolescents: the Québec family study. Int J Obes (Lond) 29: 1077-1083.
2. http://www.nwu.ac.za/webfm send/62317

3. Fairclough SJ, Stratton G (2006) Physical activity, fitness, and affective responses of normal-weight and overweight adolescents during physical education. Ped Exerc Sci18: 53-63.

4. Churchill Livingstone (2007) Armstrong $\mathrm{N}$ and British Association of Sport and Exercise Sciences. Paediatric exercise physiology, Edinburgh, New York.

5. Ortega FB, Ruiz JR, Hurtig-Wennlöf A, Sjöström M (2008) [Physically active adolescents are more likely to have a healthier cardiovascular fitness leve independently of their adiposity status. The European youth heart study]. Rev Esp Cardiol 61: 123-129.

6. Ruiz JR, Castro-Piñero J, España-Romero V, Artero EG, Ortega FB, et al. (2011) Field-based fitness assessment in young people: the ALPHA healthrelated fitness test battery for children and adolescents. Br J Sports Med 45 : 518-524.

7. Andersen LB, Riddoch C, Kriemler S, Hills AP (2011) Physical activity and cardiovascular risk factors in children. Br J Sports Med 45: 871-876.

8. Dwyer T, Magnussen CG, Schmidt MD, Ukoumunne OC, Ponsonby AL, et al. (2009) Decline in physical fitness from childhood to adulthood associated with increased obesity and insulin resistance in adults. Diabetes Care 32: 683-687.

9. Boreham C, Riddoch C (2001) The physical activity, fitness and health of children. J Sports Sci 19: 915-929.

10. Breslin G, Gossrau-Breen D, McCay N, Gilmore G, McDonald L, et al. (2012 Physical activity, gender, weight status, and wellbeing in 9- to 11-year-old children: a cross sectional survey. J Phys Act Health 9: 394-401.

11. The Scottish Government (2012) The Scottish Health Survey Volume 2: Children. The Scottish Government, Edinburgh, UK.

12. Janssen I (2007) [Guidelines for physical activity in children and young people] Appl Physiol Nutr Metab 32 Suppl 2F: S122-135

13. Caballero B (2007) The global epidemic of obesity: an overview. Epidemiol Rev 29: $1-5$.

14. Artero EG, España-Romero $V$, Ortega FB, Jiménez-Pavón $D$, Ruiz JR, et al. (2010) Health-related fitness in adolescents: underweight, and not only overweight, as an influencing factor. The AVENA study. Scand J Med Sci Sports 20: $418-427$

15. Cole TJ, Bellizzi MC, Flegal KM, Dietz WH (2000) Establishing a standard definition for child overweight and obesity worldwide: international survey. BMJ 320: $1240-1243$.

16. Ledoux M, Lambert J, Reeder BA, Després JP (1997) A comparative analysis of weight to height and waist to hip circumference indices as indicators of the presence of cardiovascular disease risk factors. Canadian Heart Health Surveys Research Group. CMAJ 157 Suppl 1: S32-38.

17. Crocker PR, Bailey DA, Faulkner RA, Kowalski KC, McGrath R (1997) Measuring general levels of physical activity: preliminary evidence for the Physical Activity Questionnaire for Older Children. Med Sci Sports Exerc 29: 1344-1349.

18. Léger LA, Mercier D, Gadoury C, Lambert J (1988) The multistage 20 metre shuttle run test for aerobic fitness. J Sports Sci 6: 93-101.

19. Kilding AE, Aziz AR, Teh KC (2006) Measuring and predicting maximal aerobic power in international-level intermittent sport athletes. J Sports Med Phys Fitness 46: 366-372.

20. Hoekstra T, Boreham CA, Murray LJ, Twisk JW (2008) Associations between aerobic and muscular fitness and cardiovascular disease risk: the northern Ireland young hearts study. J Phys Act Health 5: 815-829.

21. Moliner-Urdiales D, Ruiz JR, Vicente-Rodriguez G, Ortega FB, Rey-Lopez JP, et al. (2011) Associations of muscular and cardiorespiratory fitness with total and central body fat in adolescents: the HELENA study. Br J Sports Med 45: 101-108.

22. Sveinsson T, Arngrimsson SA, Johannsson E (2009) Association between aerobic fitness, body composition, and physical activity in 9- and 15-year-olds. Eur J Sports Sci 9: 141-150.

23. Molenaar HM, Selles RW, Zuidam JM, Willemsen SP, Stam HJ, et al. (2010) Growth diagrams for grip strength in children. Clin Orthop Relat Res 468: 217 223.

24. Ortega FB, Ruiz JR, Castillo MJ, Sjöström M (2008) Physical fitness in 
Citation: Gray DT, Baker JS, Buchan DS (2013) Weight Status, Physical Activity and the Associations with Health Related Physical Fitness in Nine to Twelve Year Old Scottish Children. J Sports Med Doping Stud 3: 129. doi:10.4172/2161-0673.1000129

Page 5 of 5

childhood and adolescence: a powerful marker of health. Int $\mathrm{J}$ Obes (Lond) 32: 1-11.

25. Breslin G, Gossrau-Breen D, McCay N, Gilmore G, McDonald L, et al. (2012) Physical activity, gender, weight status, and wellbeing in 9- to 11-year-old children: a cross sectional survey. J Phys Act Health 9: 394-401.

26. Young-So W, Choi DH (2010) Differences in physical fitness and cardiovascular function depend on BMI in Korean men. J Sports Sci and Med. 9: 239-244.

27. Grund A, Dilba B, Forberger K, Krause H, Siewers M, et al. (2000) Relationships between physical activity, physical fitness, muscle strength and nutritional state in 5- to 11-year-old children. Eur J Appl Physiol 82: 425-438.

28. Christodoulos AD, Douda HT, Tokmakidis SP (2012) Cardiorespiratory fitness, metabolic risk, and inflammation in children. Int J Pediatr 2012: 270-515.

29. Martins CL, Silva F, Gaya AR, Aires L, Ribeiro JC, et al. (2010) Cardiorespiratory fitness, fatness, and cardiovascular disease risk factors in children and adolescents from Porto. Eur J Sports Med 10: 121-127.

30. Resaland GK, Mamen A, Boreham C, Anderssen SA, Andersen LB (2010)
Cardiovascular risk factor clustering and its association with fitness in nineyear-old rural Norwegian children. Scand J Med Sci Sports 20: e112-120.

31. Deforche B, Lefevre J, De Bourdeaudhuij I, Hills AP, Duquet W, et al. (2003) Physical fitness and physical activity in obese and nonobese Flemish youth Obes Res 11: 434-441.

32. Ruiz JR, Rizzo NS, Hurtig-Wennlöf A, Ortega FB, Wärnberg J, et al. (2006) Relations of total physical activity and intensity to fitness and fatness in children: the European Youth Heart Study. Am J Clin Nutr 84: 299-303.

33. Malina RM, Beunen GP, Classens AL, Lefevre J, Vanden Eynde BV, et al (1995) Fatness and physical fitness of girls 7 to 17 years. Obes Res 3: 221-231. 